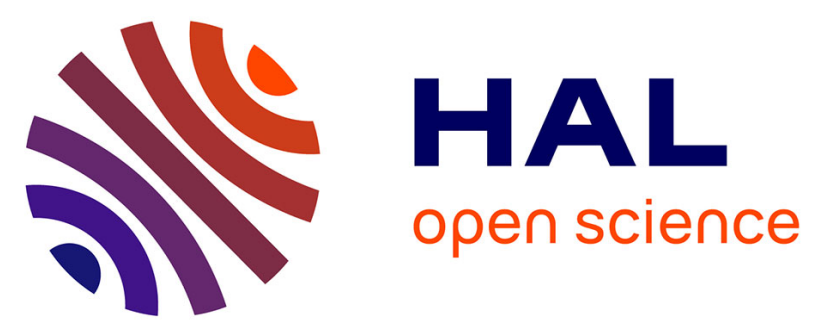

\title{
Development of a physiologically based kinetic model for 99m-Technetium-labelled carbon nanoparticles inhaled by humans
}

\author{
Alexandre R.R. Pery, Céline Brochot, Peter Hoet, Abderrahim Nemmar, \\ Frédéric Y. Bois
}

\section{To cite this version:}

Alexandre R.R. Pery, Céline Brochot, Peter Hoet, Abderrahim Nemmar, Frédéric Y. Bois. Development of a physiologically based kinetic model for 99m-Technetium-labelled carbon nanoparticles inhaled by humans. Inhalation Toxicology, 2009, 21 (13), pp.1099-1107. 10.3109/08958370902748542 . ineris-00961947v2

HAL Id: ineris-00961947

https://hal-ineris.archives-ouvertes.fr/ineris-00961947v2

Submitted on 29 Apr 2014

HAL is a multi-disciplinary open access archive for the deposit and dissemination of scientific research documents, whether they are published or not. The documents may come from teaching and research institutions in France or abroad, or from public or private research centers.
L'archive ouverte pluridisciplinaire HAL, est destinée au dépôt et à la diffusion de documents scientifiques de niveau recherche, publiés ou non, émanant des établissements d'enseignement et de recherche français ou étrangers, des laboratoires publics ou privés. 
Development of a physiologically-based kinetic model for 99m-Technetium labelled carbon nanoparticles inhaled by humans

\section{Alexandre RR Péry}

Ineris, Verneuil-en-Halatte, France

Céline Brochot

Ineris, Verneuil-en-Halatte, France

Peter HM Hoet

K.U. Leuven, Leuven, Belgium

Abderrahim Nemmar

United Arab Emirates University, Al-ain, United Arab Emirates

Frédéric Y Bois

Ineris, Verneuil-en-Halatte, France

Address correspondence to Alexandre Péry, INERIS, Parc Alata, BP 2, 60550 Verneuil-enHalatte, France. E-mail address: alexandre.pery@ineris.fr.

Running Head : Human PBPK model for carbon nanoparticles. 


\begin{abstract}
Particulate air pollution is associated with respiratory and cardiovascular morbidity and mortality. Recent studies investigated whether and to which extent inhaled ultrafine particles are able to translocate into the bloodstream in humans. However, their conclusions were conflicting. We developed a physiologically based kinetic model for ${ }^{99} \mathrm{~m}_{\text {technetium-labelled }}$ carbon nanoparticles $\left(\right.$ Technegas $\left.^{\circledR}\right)$. The model was designed to analyse imaging data. It includes different translocation rates and kinetics for free technetium, and small and large technetium-labeled particles. It was calibrated with data from an experiment designed to assess the fate of nanoparticles in humans after inhalation of Technegas ${ }^{\circledR}$. The data provided time-courses of radioactivity in the liver, stomach, urine and blood. Parameter estimation was performed in a Bayesian context with Markov Chain Monte Carlo (MCMC) techniques. Our analysis points to a likely translocation of particle-bound technetium from lung to blood, at a rate about 2-fold lower than the transfer rate of free technetium. Notably, restricting the model so that only free technetium would have been able to reach blood circulation result in much poorer fits to the experimental data. The percentage of small particles able to translocate was estimated at $12.7 \%$ of total particles. The percentage of unbound technetium was estimated at $6.7 \%$ of total technetium. To our knowledge, our model is the first PBPK model able to use imaging data to describe the absorption and distribution of nanoparticles. We believe that our modeling approach using Bayesian and MCMC techniques provides a reasonable description on which to base further model refinement.
\end{abstract}




\section{INTRODUCTION}

Nanoparticles' safety is an integral part of their development process. We regularly witness the publication of reports on their toxicity effects in vitro, which beg for the question of their significance in vivo (Oberdörster et al., 2005 ; Sayes et al., 2007). A crucial point to answer is to what extent and at what rate nanoparticles enter the body and distribute in its various tissues. The issue is controversial because nanoparticles are larger than most molecules known to penetrate easily in the body, because there are little data on the topic, and because the few published results conflict, even for the same type of nanoparticles (Odajima et al., 2008). Nemmar et al. (2002) and Mills et al. (2006) exposed healthy non-smoking volunteers

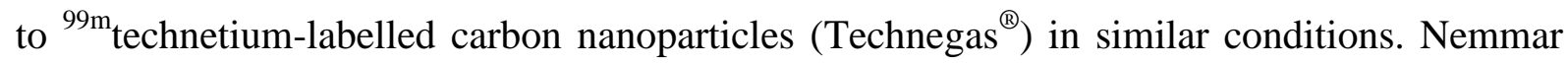
et al. concluded that nanoparticles translocated from the lung into the blood circulation. Mills et al., however, found no evidence to support that claim, reporting that most of their observed data were explained by the distribution of free technetium (Tc), unbound to nanoparticles. They suggested many explanations for Nemmar et al. (2002) data, such as the need to ccount for free technetium kinetics and the fact that in imaging data, several overlapping regions contribute to radioactivity in the regions of interest. For instance, the radioactivity measured in liver is partially related to technetium concentration in the lung, the skin, the blood and adipose tissues. It seems consequently crucial to re-analyse Nemmar et al. data with tools able to analyse imaging data and estimate relevant kinetics parameters.

Therefore, we developed a physiologically based pharmacokinetic (PBPK) model, adapted to imaging data analysis, which proposes a realistic, even if simplified, description of the mechanisms of absorption, distribution and elimination of technetium-labeled nanoparticles and free technetium in the body. In PBPK models, the body is subdivided into various compartments representing specific organs linked by blood flows. Compartments are characterized by a set of parameters of physiological relevance (e.g., volume and blood 
perfusion rate) which play a crucial role in explaining the behavior of chemical substances in the body, and are invariant across substances. PBPK models offer great flexibility. In particular, they are adapted to extrapolations between species, routes or dose levels (Chiu et al., 2007). The general PBPK model we proposed was applied to the Nemmar et al. inhalation study, with parameters estimation in a Bayesian context. The Bayesian approach is a suitable method in the context of mechanistic pharmacokinetic modelling, as they are well suited for efficient use of both data and prior knowledge regarding the compound or the physiology of the subjects. This permits a reliable parameter estimation for a complex PBPK model such as the one used there.

\section{MATERIALS AND METHODS}

\section{Data}

Nemmar et al. collected Technegas ${ }^{\circledR}$ distribution data on 5 healthy male volunteers from 24 to 47 years old. Technegas ${ }^{\circledR}$ is an aerosol suspension of ${ }^{99 \mathrm{~m}}$ Tc-labelled carbon particles produced in high purity argon. The size of individual particles was 5 to $10 \mathrm{~nm}$, confirmed by electron microscopy. Volunteers were exposed to approximately $100 \mathrm{MBq}$ of Technegas ${ }^{\circledR}$ in 3 to 5 breaths. Blood radioactivity data were collected at 1, 5, 10, 20, 30, 45 and 60 minutes after Technegas ${ }^{\circledR}$ inhalation, together with gamma-camera images of radioactivity distribution in the whole body measured at 5, 10, 20, 30 and 45 minutes. Three regions of interest (liver, stomach lumen, bladder content, i.e. urine) were defined on the images. We disposed of their intensity apportioned to liver intensity at 5 minutes. We did not use directly intensity apportioned to initial lung radioactivity, as shown in Nemmar et al. figure 2, because of the very high variability of this measurement among the five subjects. 


\section{PBPK Model}

The basic model structure is presented in Figure 1, with the whole systems of equations detailed in the Appendix. It subdivides the human male body into 24 compartments. This number of compartments have been included because imaging data analysis decompose imaging regions of interest into many compartments (See next paragraph). However, we used a common partition coefficient between organs and blood and the blood fluxes in organs were fixed to reference values to avoid overparametrisation of the model.

As PBPK models deal with organ concentrations, prior to parameters estimation, we had to relate the observed data (relative gamma emission intensity or radioactive decay counts) to organ concentrations. We defined regions of interest (ROIs) for various organs on a projection of a voxel-based anthropomorphic phantom (Zubal et al., 2001). We then counted the voxels pertaining to the various tissues and empty space around the body in the volume defined by an ROI, and formed the ratios of those counts to the total number of voxel in the volume considered. Then, we could relate mathematically ROI intensity and concentrations in organs and blood (See Appendix).

In our model, intake of nanoparticles occurs initially through breathing. Particles are deposited in the upper respiratory tract and lungs. Some are rapidly transferred to the stomach, due to the swallowing of particles deposited in the mouth (Nemmar et al., 2002). In our model, there was consequently a fixed initial condition with a fixed quantity of particles and free technetium in the stomach and a fixed one in the lung. As actual exposure dose was uncertain, this parameter was among the ones we estimated from the data. Technegas ${ }^{\circledR}$ is not homogeneous. Indeed, part of the technetium is unbound and particles have different sizes, which can induce different kinetics. We distinguished between three different fractions: ${ }^{99 \mathrm{~m}} \mathrm{Tc}$ bound to small particles (i.e. able to translocate), ${ }^{99 \mathrm{~m}} \mathrm{Tc}$ bound to large particles (i.e. unable to translocate) and free ${ }^{99 \mathrm{~m}} \mathrm{Tc}$. The concomitant distribution of ${ }^{99 \mathrm{~m}} \mathrm{Tc}$ in these three fractions was 
modeled. Large particles are assumed to remain at constant concentration in the lung and the stomach, as suggested by many publications (Mills et al., 2005; Wiebert et al., 2006). Small particles and free ${ }^{99 \mathrm{~m}} \mathrm{Tc}$ in the lung can transfer to blood by diffusion. Moreover, free ${ }^{99 \mathrm{~m}} \mathrm{Tc}$ can translocate from the lung into the gastrointestinal tract as shown by Wiebert et al. (2006). This was accounted for in the model, in which we also assumed that this translocation was possible for small nanoparticles. Once in the blood, small particles and free ${ }^{99 \mathrm{~m}} \mathrm{Tc}$ diffuse to the various compartments (except the brain, because Nemmar data show no transfer of ${ }^{99 \mathrm{~m}} \mathrm{Tc}$ to that organ). Elimination of free ${ }^{99 \mathrm{~m}} \mathrm{Tc}$ is supposed to occur by filtration to urine. During the time of exposure $(60 \mathrm{~min})$, the renal elimination of particle bound $-{ }^{99 \mathrm{~m}} \mathrm{Tc}$ was neglected, as there was only free ${ }^{99 \mathrm{~m}} \mathrm{Tc}$ found in urine (Nemmar et al., 2002). To facilitate parameters estimation, we assumed that all organs have the same blood over tissue partition coefficient value. Some studies have shown that accumulation of ${ }^{99 m} \mathrm{Tc}$ is similar in most of the organs (ICRP, 1999).

Applying the law of mass conservation for each organ or tissues yields for each model a set of differential equations (see Appendix), which were solved by numerical integration using the MCSim software version 5.0.0 (Bois and Maszle, 1997) (see http://fredomatic.free.fr/page_mcsim.html). The models can be used to simulate the time course of radioactivity associated with ${ }^{99 \mathrm{~m}} \mathrm{Tc}$-labeled nanoparticles and free ${ }^{99 \mathrm{~m}} \mathrm{Tc}$ in the various body compartments, as a function of the quantity of Tc inhaled and of various physiological characteristics of the body.

The PBPK model parameters, and some additional parameters needed to describe the data collection process, are described together with the model equations in Supporting Information. For physiological parameters (such as organ volumes and blood flows), we used the fixed values given in Tables 1 and 2, which are common values for adult males. Parameters specific to Technegas ${ }^{\circledR}$ or to the experiments performed were treated as random 
variables in a Bayesian statistical framework (as detailed below), and their prior sampling distributions are given in Table 3.

\section{Statistical analysis}

A statistical measurement error model and a population model were needed to assign values for some of the parameters given in Table 3 given their prior distributions and Nemmar et al. data. The measurement error model described modeling errors and uncertainties in the data collection process (e.g., in the fraction of the particles immediately swallowed, imprecise quantity of inhaled Tc, approximate definition of the regions of interest scanned). Interindividual variability was quantified in the framework of a population model (Gelman et al., 1996; Bernillon and Bois, 2000) to try to account for the fact that the five subjects studied clearly differed from a kinetic standpoint (see for example in Figure 3 the differences in blood radioactivity counts between subjects given the same exposure).

For a given PBPK model, the measurement errors in blood radioactivity counts were assumed to be independent and log-normally distributed, with a geometric mean equal to the PBPK model predictions and a geometric standard deviation (GSD) of 1.05 (approximately 5\% error). The same was assumed for the relative intensities in liver, stomach, and urine, but with a GSD of 1.15. Data likelihoods were therefore given by:

$$
\log (Y) \sim N\left(\log (F(X, \theta)), \sigma_{c}\right)
$$

where the function $F(X, \theta)$ corresponds to a PBPK model with input $\mathrm{X}$ and parameters $\theta$, and $\sigma_{c}$ is equal to either 1.05 or 1.15 .

Pharmacokinetic models and error models were embedded in a hierarchical population structure, which considers that each subject's parameter values $\theta$ are drawn from a statistical distribution $G$ with given population mean $\mu_{\theta}$ and variance $\sigma_{\theta}$. 
The proposed population model has two major components: the individual and the population levels. At the individual level, parameters $\theta$ were assumed to be normally or log-normally distributed with population means $\mu_{\theta}$ and standard deviations $\sigma_{\theta}$. Truncation bounds of the distributions were set on the basis of the limits for plausible values. The hierarchical population structure was only applied for the physiological parameters in Table 3 (fractions of lungs and volume of urine). The population distributions were normal, with normal distribution for population variances with a mean of 1.01 and a standard deviation of 1 . In contrast, partition coefficients and percentage of free Tc and of small particles were considered only as population parameters (i.e., constant across subjects). Two parameters were added at individual level, the quantity of inhaled Tc, $Q_{\text {lung }}(0)$ and the fraction of the inhaled particles immediately swallowed, $S \_f$.

\section{Bayesian Inference via MCMC}

The population model described above was fitted to the observed data with Bayesian techniques (Gelman et al., 1995). The Bayesian approach yields a sample of parameter values from their joint posterior distribution. From Bayes' theorem, the joint posterior distribution of parameters is proportional to the prior distributions of parameters multiplied by the data likelihood. The posterior is then an update, using observed data, of what it is known about parameters prior to the experiment.

The first step of the Bayesian approach consists in defining prior distributions that quantify the information coming from expertise or from the scientific literature. Prior distributions on population parameters and their associated parameters are summarized in Table 3. As little is known about nanoparticle kinetics, we generally used very wide uniform distributions to define chemical-specific parameters. We had prior information about the first-order transfer 
rate from lung to blood for free Tc (Klotzerke et al., 1996; Thomeer et al., 2002) so that we fixed $K_{v_{-} \text {lung_l } l}$ at 0.04 .

We obtained marginal posterior distributions of the model parameters in Table 3 by randomly sampling their values from the joint posterior distributions of all population and individual parameters, conditionally on the data from the 5 subjects. For this, we used Markov Chain Monte-Carlo simulations (Gilks et al., 1996) (Metropolis-Hastings sampler) performed with the MCSim software. After 80000 iterations of 3 parallel Markov chains, their convergence was checked by calculating the Gelman and Rubin $\hat{R}$ ratio on the last 20000 iterations (Gelman and Rubin, 1992).

\section{RESULTS}

The highest $\hat{R}$ computed for the last 20000 iterations was 1.05 , showing that all chains had approximately converged. To get a sample from the targeted posterior distribution, we took one in 10 vectors among the last 20000 of each chain leading to a posterior sample of 6000 parameter vectors.

Figure 2 and 3 provide the data and regression for the relative intensities of stomach and urine compared to liver and the radioactivity measured in blood. The fit is globally satisfactory but, for each figure, at least one individual dataset is badly fitted. For stomach, subject 5 dataset is very different from those of the other individuals. The ratio is almost constant during the first four time points and only increases for the last time point. For urine, subject 1 measures are underestimated. As for blood concentrations, subject 3 kinetics has not been captured by the model. It is however important to note that most of the parameters of the model are common to the five individuals, to avoid over-parameterization and difficulties for parameter estimation. Individual substantial differences for one parameter could explain the bad fit. For instance, subject 1 may have a smaller urine flow rate than the other subjects. 
We tried an alternative model with no particle (small or large) being able to reach blood circulation. This was performed by fixing at 0 the translocation rates for small particles. The resulting-Loglikelihood was doubled, and the time-courses of organ intensities and blood concentration were not captured by this alternative model, for all the subjects.

Table 4 gives posterior distribution summaries for the population parameters of the model. It appears that only a small proportion of the technetium was free (6.7\% of total technetium) but also that only a small proportion of the particles were able to reach blood circulation $(12.7 \%$ of total particles). For both parameters, the standard deviation is less than $20 \%$ of the mean value, which shows that, despite the relative low number of subjects, it was possible to have an accurate estimate for these parameters. The translocation rate of particles from lung to blood was 2-fold lower than the one of free technetium. Elimination of free technetium was rapid and translocation of free technetium from the lung into the stomach was ten times lower than its translocation in the blood. Partition coefficients were comparable for particle-bound and free technetium. As for individual parameters (data not shown), most of the initial amount of particles were in the lung, less than $4 \%$ of initially inhaled particles having being swallowed. Estimated exposures ranged from 139 to $229 \mathrm{MBq}$, greater than but consistent with the estimate $100 \mathrm{MBq}$ reported by Nemmar et al. (2002). Indeed, there were many sources of variation relative to exposure. For instance, the number of breaths varied from 3 to 5.

\section{DISCUSSION}

The adverse effect of inhaled particles on the cardiovascular system have been suggested to result from pulmonary inflammation resulting in systemic consequences and/or the direct translocation of particles from the lungs into the systemic circulation (Seaton et al., 1995; Vermylen et al., 2005). With respect to the possibility that ultrafine particles translocate 
from the pulmonary into the blood circulation, various studies have been conducted in different animal models. The amount of ultrafine particles that translocated into blood and extrapulmonary organs differs amongst these studies (Nemmar et al., 2001; Oberdörster et al., 2002; Takenaka et al., 2001).

However, the issue of particle translocation in humans is still contradictory. Brown et al. (2002) studied the deposition and clearance for $2 \mathrm{~h}$ of an $60 \mathrm{~nm}$ technetium-99m-labeled aerosol in human volunteers, and found no significant radioactivity over the liver $(1.3 \pm$ $1.2 \%)$. This activity was attributed to scatter from the lung and/or overlap of lung parenchyma in the liver. Consequently, these authors excluded the occurrence of translocation and, although they did not measure radioactivity in blood, they challenged the conclusion of Nemmar et al. (2002), that 5-10 nm technetium-labeled particles could pass from the lungs into blood and extrapulmonary organs. More recently, Mills et al. (2005) exposed healthy

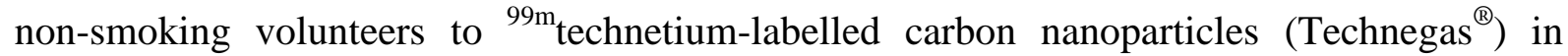
similar conditions to Nemmar's study. While the study of Nemmar et al., concluded to a translocation of nanoparticles from the lung into the blood circulation, Mills et al., however, found no evidence to support the conclusion of Nemmar et al., and have explained the findings by the distribution of free technetium (Tc), unbound to nanoparticles. Mills and colleagues investigated this question by using an aerosol of technetium-99m-labeled carbon particles (4-20 nm in diameter, but these rapidly formed aggregates of $100 \mathrm{~nm}$ in the inhaled aerosol). No significant radioactivity was found over the liver. The nature of the radioactivity found in blood (4.4\%) consisted mainly of pertechnetate, as analysed by thin layer chromatography (TLC). TLC controls of Technegas aerosol collected immediately from the generator showed clearly two peaks, one at the origin corresponding to particle-bound ${ }^{99 \mathrm{~m}} \mathrm{Tc}$ and the other at the solvent front corresponding to oxidized ${ }^{99 \mathrm{~m}} \mathrm{Tc}$, ie, pertechnetate $\left(\mathrm{TcO}_{4}{ }^{-}\right)$. Moreover, when the aerosol was added to whole blood in vitro, two peaks were observed one 
staying at the application point and the other moving with the solvent front (smaller peak). The radioactivity observed after Technegas inhalation consisted mainly in free pertechnetate, because additional in vivo oxidation may easily have occurred. No TLC analysis after the administration of free pertechnetate in humans or in vivo in animals has been reported by these authors.

These results contrasts with previous findings by Nemmar et al., also based on inhaling an aerosol of technetium-99m-labeled carbon particles, where particle-bound radioactivity (also assessed by TLC) was detected in blood already after 1 minute, reaching a maximum between 10 and 20 minutes, and remaining at this level up to 60 minutes. The TLC analysis obtained after adding blood with ${ }^{99 \mathrm{~m}} \mathrm{Tc}$-carbon particles collected from the generator showed, at $1 \mathrm{~min}$, only one peak that stayed at the origin. However, at $60 \mathrm{~min}$, in addition to the peak at the origin, the presence of a smaller peak of radioactivity at the solvent front has been observed (suggestive of in vitro oxidation). Following Technegas inhalation, TLC of all blood samples showed, in addition to radioactivity having moved with the solvent front, a substantial proportion of radioactivity that stayed at the application point and corresponded to particle-bound ${ }^{99 \mathrm{~m}} \mathrm{Tc}$. In contrast, there was only one peak at the solvent front after adding ${ }^{99 \mathrm{~m}} \mathrm{Tc}$-pertechnetate to blood or in blood collected after the intratracheal administration of ${ }^{99 \mathrm{~m}} \mathrm{Tc}$-pertechnetate to hamsters. Gamma camera images showed substantial radioactivity over the liver and other areas of the body. Consequently, the discrepancies between these two studies may be related to the Technegas particles (size and composition) from Technegas generators with a different history and age. While further studies with other types of radioactive labeling should clarify this issue, the PBPK model developed for ${ }^{99}$ technetiumlabelled carbon nanoparticles is a useful approach aimed at evaluating the translocation of nanoparticles from lungs into the systemic circulation. 
To our knowledge, our paper presents the first use of PBPK modeling to assess distribution of nanoparticles in humans, based on imaging data. It offers a reasonable description of Technegas ${ }^{\circledR}$ kinetics in humans, with a relatively low number of parameters (12 parameters). We showed how information obtained from imaging could be coupled with blood concentration measurements to update kinetics parameters distribution in a Bayesian framework. We obtained similar results relative to free technetium kinetics than other studies (ICRP, 1999; Mills et al., 2005; Wiebert et al., 2006), a high elimination rate through urine, and less than $5 \%$ of swallowed particles. The estimated fraction of unbound technetium (6.7\%) was also very coherent with the one found by Mills et al. (2005) at approximately 5\%. From our study, it appears that passage of particles (of this size and specification) from lung into the blood circulation is likely to occur, for a small number of particles, with a rate of passage half the known rate for soluble ${ }^{99 \mathrm{~m}} \mathrm{Tc}$. In the paper by Nemmar et al. (2002), there was no attempt to quantify the proportion of particles likely to enter the circulation, but suggestions of possible high levels. However, we showed here, with the same data, that only a small proportion of the particles were able to translocate. Moreover in the paper by Nemmar et al. (2002), the rapid and constant liver radioactivity they observed was presented as due to particles sequestration in Kupffer cells, with a relatively high level of radioactivity (around $10 \%)$. With our modeling approach, we showed that liver radioactivity was partly explained by the presence of lung tissues in the liver imaging region of interest. Moreover, there was no need for a specific high partition coefficient to fit the data. Wiebert et al. (2006) performed experiments with either stable or unstable labeling. In the first experiment, there was only around $0.1 \%$ of initial deposited activity detected in blood as bound to particles after 80 minutes. This result is close to the Mills study. In contrast, in the experiment with one subject exposed to unstable labeling, around $6 \%$ of initial deposited activity was found in blood as bound to particles. This result is close to our estimate for Nemmar study. This suggests that 
the percentage of particles able to translocate is very dependent on the experimental design, even if high percentages are very unlikely.

The data used form the experiments described by Nemmar et al. were not specifically collected to perform PBPK modeling. We only had data on liver, urine, stomach and blood and they only extend to 60 minutes. Moreover, the data reported on the imaging were expressed as percentage of initial lung radioactivity which is a relative imprecise measure because it is only relative and not quantitative nor specific for chemical identity. The dataset contained data of a few organs; a more detailed set, with, in particular lung radioactivity time course, would have helped us in the model assessment procedure. We also looked, in the literature, for kinetics data on free Tc kinetics, and we could only get prior information about the rate of passage from lung into blood. More information on Tc kinetics, in particular on the partition coefficient, would permit to refine the assessment of the distribution and kinetics of

free and bound ${ }^{99 \mathrm{~m}} \mathrm{Tc}$ in the model. The expectation is that this would not change our main conclusion that the observed translocation cannot be explained solely by the kinetics of free technetium.

To conclude, a model was developed that describes the inhalation and distribution of Techngas in humans as representative of carbon nanoparticles. Although lacking measured tissue-to-blood partition coefficients and independent verification to a secondary data, the modeling approach using Bayesian and MCMC techniques provides a reasonable description on which to base further model refinement.

\section{ACKNOWLEDGEMENTS}

This study was funded by the European Integrated project NANOSAFE2 (Project ID: NMP2-CT-2005-515843), supported by the Sixth Framework Programme for Research and 
Technological Development. We would like to thank two anonymous reviewers who greatly helped to improve the quality of the manuscript.

\section{REFERENCES}

Bernillon, P., and Bois, F.Y., 2000. Statistical issues in toxicokinetic modeling: a Bayesian perspective. Environ. Health Persp. 108:883-893.

Bois, F.Y., and Maszle, D. 1997. MCSim: a simulation program. J. Stat. Soft. 2(9), [http://www.stat.ucla.edu/journals/jss/v02/i09].

Brown, J.S., Zeman, K.L., and Bennett, W.D., 2002. Ultrafine particle deposition and clearance in the healthy and obstructed lung. Am. J. Respir. Crit. Care Med. 166:12401247.

Chiu, W.A., Barton, H.A., Dewoskin, R.S., Schlosser, P., Thompson, C.M., Sonawane, B., Lipscomb, J.C., and Krishnan, K., 2007. Evaluation of physiologically based pharmacokinetic models in risk assessment. J. Appl. Toxicol. 27:218-237.

Gelman, A., and Rubin, D.B., 1992. Inference from iterative simulation using multiple sequences (with discussion). Stat. Sci. 7:457-511.

Gelman, A., Carlin, J.B., Stern, H.S., and Rubin, D.B., 1995. Bayesian Data Analysis. London: Chapman \& Hall.

Gelman, A., Bois, F.Y., and Jiang, J., 1996. Physiological pharmacokinetic analysis using population modeling and informative prior distributions. J. Am. Stat. Assoc. 91:14001412.

Gilks, W.R., Richardson, S., and Spiegelhalter, D.J., 1996. Markov Chain Monte Carlo in Practice. London: Chapman \& Hall. 
I.C.R.P., 1999. Radiation dose to patients from radiopharmaceuticals. Annals of the ICRP 28 (3); Pergamon Press, Oxford, UK. International Commission on Radiological Protection, Publication 80.

I.C.R.P., 2002. Basic anatomical and physiological data for use in radiological protection: reference values; New-York: International Commission on Radiological Protection, Publication 89.

Klotzerke, J., Van den Hoff, J., Burchert, W., Wagner, T.O.F., Emter, M., and Hundeshagen, H.A., 1996. Compartmental model for alveolar clearance of pertechnegas. J. Nucl. Med. 37:2066-2071.

Leggett, R.W., and Williams, L.R., 1995. A proposed blood-circulation model for reference man. Health. Phys. 69:187-201.

Mills, N.L., Amin, N., Robinson, S.D., Anand, A., Davies, J., Patel, D., De la Fuente, J.M., Cassee, F.R., Boon, N.A., Macnee, W., Millar, A.M., Donaldson, K., and Newby, D.E., 2005. Do inhaled carbon nanoparticles translocate directly into the circulation in humans ? Am. J. Respir. Crit. Care Med. 173:426-431.

Nemmar, A., Vanbilloen, H., Hoylaerts, M.F., Hoet, P.H., Verbruggen, A., and Nemery, B., 2001. Passage of intratracheally instilled ultrafine particles from the lung into the systemic circulation in hamster. Am. J. Respir. Crit. Care Med. 164:1665-1668.

Nemmar, A., Hoet, P.H.M., Vanquickenborne, B., Dinsdale, D., Thomeer, M., Hoylaerts, M.F., Vanbilloen, H., Mortelmans, L., and Nemery, B., 2002. Passage of inhaled particles into the blood circulation in humans. Circulation 105:411-414.

Oberdörster, G., Sharp, Z., Atudorei, V., Elder, A., Gelein, R., Lunts, A., Kreyling, W., and Cox, C., 2002. Extrapulmonary translocation of ultrafine carbon particle following whole-body inhalation exposure of rats. J. Toxicol. Environ. Health A 65:1531-1543. 
Oberdörster, G., Oberdörster, E., and Oberdörster, J., 2005. Nanotoxicology: an emerging discipline evolving from studies of ultrafine particles. Env. Health. Persp. 113:823-839.

Odajima, H., Yamazaki, S., and Nitta, H., 2008. Decline in peak expiratory flow according to hourly short-term concentration of particulate matter in asthmatic children. Inhal. Toxicol. 20:1263-1272.

Sayes, C.M., Reeds, K.L., and Warheit, D.B., 2007. Assessing toxicity of fine and nanoparticles: comparing in vitro measurements to in vivo pulmonary toxicity profiles. Toxicol. Sci. 97:163-180.

Seaton, A., MacNee, W., Donaldson, K., and Godden, D., 1995. Particulate air pollution and acute health effects. Lancet 345:176-178.

Takenaka, S., Karg, E., Roth, C., Schulz, H., Ziesenis, A., Heinzmann, U., Schramel, P., and Heyder, J., 2001. Pulmonary and systemic distribution of inhaled ultrafine silver particles in rats. Environ. Health Perspect. 109 Suppl4:547-551.

Thomeer, M.J., Dehaes, B., Mortelmans, L., and Demedts, M., 2002. Pertechnegas lung clearance in different forms of interstitial lung disease. Eur. Respir. J. 19:31-36.

Vermylen, J., Nemmar, A., Nemery, B., and Hoylaerts, M.F., 2005. Ambient air pollution and acute myocardial infarction. J. Thromb. Haemost. 3:1955-1961.

Wiebert, P., Sanchez-Crespo, A., Falk, R., Philipson, K., Lundin, A., Larsson, S., Moller, W., Kreyling, W.G., and Svartengren, M., 2006. No significant translocation of inhaled 35$\mathrm{nm}$ carbon particles to the circulation in humans. Inhal. Toxicol. 18:741-747.

Williams, L.R., and Leggett RW., 1989. Reference values for resting blood flow to organs of man. Clin. Phys. Physiol. Meas. 10:187-217. 
Zubal, I.G., Harell C.R., Smith E.O., Smith A.L., 2001. Two dedicated software, voxel-based,

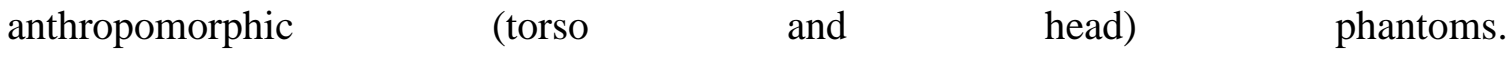

http://noodle.med.yale.edu/pubpapers/Zubal.pdf 


\section{APPENDIX : PBPK model equations}

The following equations are for the quantities $Q$ of ${ }^{99 \mathrm{~m}} \mathrm{Tc}$-labeled nanoparticles and free ${ }^{99 \mathrm{~m}} \mathrm{Tc}$ in each compartment. Quantities were expressed in $\mathrm{MBq}$, which is the unit of radioactivity used in Nemmar et al. paper. Concentrations $C$, in $\mathrm{MBq} / \mathrm{L}$, were obtained at any time by dividing $Q$ by the compartment volume. Volumes were in L, time in min, flows and rates in L/min. $Q$ and $C$ depended on time but we omit the time argument when possible for lighter notation. A list of parameters and their values can be found in Tables 1-3 of the main text.

For adipose tissue, adrenals, bone marrow, brain, breast, heart, kidneys, muscles, other organs and tissues, pancreas, skin, spleen, testes and thyroid:

$$
\frac{\partial Q_{i}}{\partial t}=F_{i} \times\left(C_{a r t}-\frac{C_{i}}{P_{i}}\right)
$$

where $F_{i}$ are defined in Table 2, and $P_{i}$ are tissue over blood partition coefficients (Table 3). For the lung:

$$
\frac{\partial Q_{\text {lung }}}{\partial t}=-\left(K_{m_{-} \text {lung }}+K_{v_{-} \text {lung }}\right) \times C_{\text {lung }}
$$

where $K_{v_{-} \text {lung }}$ and $K_{m_{-} \text {lung }}$ are respectively the direct transfer rate from lung to blood and the translocation rate from lung to stomach lumen (in L/min). Initial dose in the lung, $Q_{\text {lung }}(0)$ is one of the parameters and is estimated from the data for each of the subjects.

For the liver, blood feeds from the arterial pool, spleen, pancreas, stomach and gut:

$$
\begin{aligned}
\frac{\partial Q_{\text {liver }}}{\partial t}= & F_{\text {eport }} \times C_{\text {art }}+F_{\text {spleen }} \times \frac{C_{\text {spleen }}}{P_{\text {spleen }}}+F_{\text {pancreas }} \times \frac{C_{\text {pancreas }}}{P_{\text {pancreas }}}+F_{\text {gut }} \times \frac{C_{\text {gut }}}{P_{\text {gut }}} \\
& +F_{\text {stomach }} \times \frac{C_{\text {stomach }}}{P_{\text {stomach }}}-F_{\text {liver }} \times \frac{C_{\text {liver }}}{P_{\text {liver }}}
\end{aligned}
$$

Total blood flow to the liver, $F_{\text {liver }}$, is the sum of extra-portal flow and incoming flows from spleen, pancreas, gut and stomach: 


$$
F_{\text {liver }}=F_{\text {eport }}+F_{\text {spleen }}+F_{\text {pancreas }}+F_{\text {gut }}+F_{\text {stomach }}
$$

For urine:

$$
\frac{\partial Q_{\text {urine }}}{\partial t}=K_{e_{-} r e n a l} \times C_{v e n}
$$

where $K_{e_{-} \text {renal }}$ is the urinary clearance rate (in $\mathrm{L} / \mathrm{min}$ ).

For arterial blood:

$$
\frac{\partial Q_{a r t}}{\partial t}=F_{\text {total }} \times C_{v e n}+K_{v_{-} \text {lung }} \times C_{\text {lung }}-F_{\text {total }} \times C_{a r t}
$$

For venous blood:

$$
\frac{\partial Q_{v e n}}{\partial t}=\sum_{i}\left[F_{i} \times \frac{C_{i}}{P_{i}}\right]-F_{\text {total }} \times C_{v e n}-K_{e_{-} \text {renal }} \times C_{v e n}
$$

where $i$ designate the following organs or tissues: adipose tissue, adrenals, bone marrow, brain, breast, heart, kidneys, liver, muscles, other organs and tissues, skin, testes and thyroid The gastro-intestinal tract is described by four compartments:

$$
\begin{gathered}
\frac{\partial Q_{\text {stom_lumen }}}{\partial t}=K_{m_{-} \text {lung }} \times C_{\text {lung }}-F_{\text {stom_lumen }} \times C_{\text {stom_lumen }} \\
\frac{\partial Q_{\text {stomach }}}{\partial t}=F_{\text {stomach }} \times\left(C_{\text {art }}-\frac{C_{\text {stomach }}}{P_{\text {stomach }}}\right) \\
\frac{\partial Q_{\text {gut_lumen }}}{\partial t}=F_{\text {stom_lumen }} \times C_{\text {stom_lumen }}-F_{\text {gut_lumen }} \times C_{\text {gut_lumen }} \\
\frac{\partial Q_{\text {gut }}}{\partial t}=F_{\text {gut }} \times\left(C_{\text {art }}-\frac{C_{\text {gut }}}{P_{\text {gut }}}\right)
\end{gathered}
$$


where $F_{\text {stom_lumen }}$ is the transport rate from the stomach lumen to the gut lumen $(\mathrm{L} / \mathrm{min})$. These transport rates were assumed to negligible during the experiment.

As part of the inhaled particles have been swallowed, we introduced a parameter $\left(S \_f\right)$ so that $Q_{\text {stom_lumen }}(0)=S \_f \cdot Q_{\text {lung }}(0)$. This parameter is estimated for all subjects.

We had first to relate the observed data (relative gamma emission intensity or radioactive decay counts) to the above quantities or concentrations. We defined regions of interest (ROIs) for various organs on a projection of a voxel-based anthropomorphic phantom (The Zubal Phantom - VoxelBased Anthropomorphic Phantoms - [http://noodle.med.yale.edu/zubal/index.htm]). We then counted the voxels pertaining to the various tissues and empty space around the body in the volume defined by an ROI, and formed the ratios of those counts to the total number of voxel in the volume considered.

The following table gives the fractions estimated (they do not add up to 1 since minor tissues and empty space are excluded):

\begin{tabular}{lllll}
\hline Tissue & "Lung" & "Liver" & $\begin{array}{l}\text { Region Of Interest } \\
\text { "Stomach } \\
\text { lumen" }\end{array}$ & "Bladder" \\
& & & & \\
\hline Adipose & 0.05 & 0.05 & 0.09 & 0.14 \\
Liver & - & 0.39 & - & \\
Lung & 0.44 & $($ estimated) & (estimated) & - \\
Muscle & 0.1 & 0.1 & 0.13 & 0.08 \\
Skin & 0.02 & 0.02 & 0.02 & 0.02 \\
Spleen & - & - & 0.1 & - \\
Stomach lumen & - & - & 0.23 & - \\
Urine & - & - & - & 0.17
\end{tabular}

We account for the blood present in the organs, which contributes to the intensity of radioactivity of the studied organs. The blood volume per organ was obtained from Leggett and Williams (1995) who provide blood content in percentage of total blood volume for a reference middle-aged man. In the equations for intensity, we added the blood contribution when it could be substantial, i.e. in liver (31\%), lung (140\%), spleen (52\%).

The intensities at time $t$ in liver, stomach lumen and urine were computed similarly: 


$$
\begin{aligned}
I_{\text {liver }}(t)= & K_{\text {intensity }} \times \exp \left(-K_{d} \cdot t\right) \\
& \left(f(\text { adipliver }) \cdot C_{\text {adip }}(t)+f(\text { liver,liver }) \cdot\left(C_{\text {liver }}(t)+0.31 \cdot\left(0.33 \cdot C_{\text {art }}(t)+0.67 \cdot C_{\text {ven }}(t)\right)\right)\right. \\
& +f(\text { lungliver }) \cdot\left(C_{\text {lung }}(t)+1.4 \cdot\left(0.33 \cdot C_{\text {art }}(t)+0.67 \cdot C_{\text {ven }}(t)\right)\right. \\
& \left.+f(\text { muscleliver }) \cdot C_{\text {muscle }}(t)+f(\text { skinliver }) \cdot C_{\text {skin }}(t)\right)
\end{aligned}
$$

$$
\begin{aligned}
I_{\text {stl }}(t)= & K_{\text {intensity }} \times \exp \left(-K_{d} \cdot t\right) \\
& \times\left(f(\text { adip, stl }) \cdot C_{\text {adip }}(t)+f(\text { lung, stl }) \cdot\left(C_{\text {lung }}(t)+1.4 \cdot\left(0.33 \cdot C_{\text {art }}(t)+0.67 \cdot C_{\text {ven }}(t)\right)\right)\right. \\
& +f(\text { musclest }) \cdot C_{\text {muscle }}(t)+f(\text { skin, stl }) \cdot C_{\text {skin }}(t) \\
+ & \left.f(\text { spleen } s t l) \cdot\left(C_{\text {spleen }}(t)+0.52 \cdot\left(0.33 \cdot C_{\text {art }}(t)+0.67 \cdot C_{\text {ven }}(t)\right)\right)+f(\text { stl, stl }) \cdot C_{\text {stom_lumen }}(t)\right) \\
I_{\text {urine }}(t)= & K_{\text {intensity }} \times \exp \left(-K_{d} \cdot t\right) \times\left(f(\text { adip, urine }) \cdot C_{\text {adip }}(t)+f(\text { muscle }, \text { urine }) \cdot C_{\text {muscle }}(t)\right. \\
& \left.+f(\text { skin, urine }) \cdot C_{\text {skin }}(t)+f(\text { urine }, \text { urine }) \cdot Q_{\text {urine }}(t) / V_{\text {urine }}(t)\right)
\end{aligned}
$$

where $K_{\text {intensity }}$ is a proportionality constant, $\mathrm{K}_{\mathrm{d}}$ is the decay rate constant for ${ }^{99 \mathrm{~m}} \mathrm{Tc}(0.001922$ $\min ^{-1}$, ), and $f(i, j)$ the fraction of tissue $i$ present in a ROI labeled $j$.

$V_{\text {urine }}(t)$ is the volume of urine (in $\mathrm{L}$ ) at time $t$, computed as:

$$
V_{\text {urine }}(t)=V_{\text {urine }}(0)+F_{\text {urine }} \times t
$$

where $V_{\text {urine }}(0)$ is the volume of urine (in L) in the bladder at the start of exposure and $F_{\text {urine }}$ is the urinary flow rate $(\mathrm{L} / \mathrm{min})$.

The recorded radioactivity counts in blood (in CPM/g of blood) where obtained from $C_{v e n}$ (in $\mathrm{MBq} / \mathrm{L})$ by:

$$
C_{r_{-} v e n}(t)=60000 \times C_{v e n}(t) \times \exp \left(-K_{d} \cdot t\right)
$$

The number 60000 comes from the conversion from MBq/L in CPM/g.

We described jointly the kinetics of small particles-bound $-{ }^{99 \mathrm{~m}} \mathrm{Tc}$ and free ${ }^{99 \mathrm{~m}} \mathrm{Tc}$. We introduced the fraction of ${ }^{99 \mathrm{~m}} \mathrm{Tc}$ bound, Bound, and the fraction of small particles, Small, as model parameters and defined two set of variables (the concentrations related to large 
particles-bound- ${ }^{99 \mathrm{~m}} \mathrm{Tc}$ are constant over time, so that there is no use to define a set of variables for them). Variables $Q_{i \_}$corresponded to ${ }^{99 \mathrm{~m}} \mathrm{Tc}$ bound to small particles (i.e., labeled nanoparticles) in each compartment, with $Q_{i_{-} l}$ corresponding to free ${ }^{99 \mathrm{~m}} \mathrm{Tc}$. Similarly, we defined concentration sets $C_{i_{-} 0}$ and $C_{i_{-} l}$ in $\mathrm{MBq} / \mathrm{L}$.

The inhaled small particles-bound- ${ }^{99 \mathrm{~m}} \mathrm{Tc}$ and unbound- ${ }^{99 \mathrm{~m}} \mathrm{Tc}$ concentrations were functions of the total concentration inhaled $C_{i n h}$ :

$$
\begin{gathered}
C_{i n h_{-} 0}=\text { Bound } \times \text { Small } \times C_{i n h} \\
C_{i n h_{-} l}=(1-\text { Bound }) \times C_{i n h}
\end{gathered}
$$

Equations 1 to 3 , and 5 to 11 were duplicated (one set for bound ${ }^{99 \mathrm{~m}} \mathrm{Tc}$, the other for free ${ }^{99 \mathrm{~m}} \mathrm{Tc}$ ). Output equations 12 to 14 and 16 did not change, and the concentrations $C_{\text {adip }}, C_{\text {lung }}$, $C_{\text {liver }}$, etc. of total ${ }^{99 \mathrm{~m}} \mathrm{Tc}$ which they use were at each time computed as the sum of the bound (to small and large particles) and free concentrations. 


\section{TABLE 1}

Organ or tissue volumes calculated for a standard man of $1.76 \mathrm{~m}$ and $73 \mathrm{~kg}$, using the organ weights given by the ICRP 2002 Pub 89 (Table 2.8 p.18; Table 2.9 p.19). Density for the organs is supposed equal to 1 excepted for adipose tissues (density 0.9 ) and bones (density 2)

\begin{tabular}{llc}
\hline Tissue or organ & Symbol & Value (L) \\
\hline Adipose & $V_{\text {adip }}$ & 18.8 \\
Adrenals & $V_{\text {adrenal }}$ & 0.014 \\
Arterial blood & $V_{\text {art }}$ & 1.40 \\
Venous blood & $V_{\text {ven }}$ & 4.20 \\
Bone & $V_{\text {bone }}$ & 2.75 \\
Brain & $V_{\text {brain }}$ & 1.45 \\
Breast & $V_{\text {breast }}$ & 0.025 \\
Gut & $V_{\text {gut }}$ & 1.02 \\
Gut lumen & $V_{\text {gut_lumen }}$ & 0.65 \\
Heart & $V_{\text {heart }}$ & 0.33 \\
Kidney & $V_{\text {kidney }}$ & 0.31 \\
Liver & $V_{\text {liver }}$ & 1.80 \\
Lung & $V_{\text {lung }}$ & 0.50 \\
Bone marrow & $V_{\text {marrow }}$ & 3.65 \\
Muscles & $V_{\text {muscle }}$ & 29.0 \\
Others & $V_{\text {other }}$ & 7.06 \\
Pancreas & $V_{\text {pancreas }}$ & 0.14 \\
Skin & $V_{\text {skin }}$ & 3.30 \\
Spleen & $V_{\text {spleen }}$ & 0.15 \\
Stomach & $V_{\text {stomach }}$ & 0.15 \\
Stomach lumen & $V_{\text {stom_lumen }}$ & 0.25 \\
Testes & $V_{\text {testes }}$ & 0.056 \\
Thyroid & $V_{\text {thyroid }}$ & 0.019 \\
\hline & &
\end{tabular}




\section{TABLE 2}

Urine flow rate and blood flows for the various organs or tissues. These have been computed using cardiac output, percent blood flows per tissue mass and organ weights given in ICRP 2002 Pub 89 (Table 2.8 p18-19, Table 2.39 p28, Table 2.40 p29) or provided by William \& Leggett (1989).

\begin{tabular}{llc}
\hline Tissue or organ & Symbol & Value $(\mathbf{L} /$ min $)$ \\
\hline Adipose & $F_{\text {adip }}$ & 0.564 \\
Adrenals & $F_{\text {adrenal }}$ & 0.02 \\
Brain & $F_{\text {brain }}$ & 0.78 \\
Breast & $F_{\text {breast }}$ & 0.00 \\
Gut & $F_{\text {gut }}$ & 0.98 \\
Heart & $F_{\text {heart }}$ & 0.35 \\
Kidney & $F_{\text {kidney }}$ & 1.23 \\
Liver & $F_{\text {eport }}$ & 0.45 \\
Lung & $F_{\text {total }}$ & 6.72 \\
Bone marrow & $F_{\text {marrow }}$ & 0.29 \\
Muscles & $F_{\text {muscle }}$ & 1.11 \\
Others & $F_{\text {other }}$ & 0.19 \\
Pancreas & $F_{\text {pancreas }}$ & 0.065 \\
Skin & $F_{\text {skin }}$ & 0.33 \\
Spleen & $F_{\text {spleen }}$ & 0.19 \\
Stomach & $F_{\text {stomach }}$ & 0.065 \\
Testes & $F_{\text {testes }}$ & 0.004 \\
Thyroid & $F_{\text {thyroid }}$ & 0.094 \\
Urine flow rate & $F_{\text {urine }}$ & 0.001 \\
\hline
\end{tabular}


TABLE 3

MCMC-sampled physiological or experiment-specific parameters. Population distributions.

references ICRP 2002 Pub 89, p.99.

\begin{tabular}{|c|c|c|c|}
\hline Parameter & Symbol & Distribution & Unit \\
\hline $\begin{array}{lll}\text { Quantity of } & \text { inhaled } \\
\text { Technetium } & & \end{array}$ & $Q_{\text {lung }}(0)$ & Uniform $(0,300)$ & $\mathrm{MBq}$ \\
\hline $\begin{array}{l}\text { Fraction of the inhaled particles } \\
\text { immediately swallowed }\end{array}$ & $S \_f$ & Uniform $(0,0.2)$ & - \\
\hline $\begin{array}{l}\text { Volume of urine in bladder at } \\
\text { start of exposure }\end{array}$ & $V_{\text {urine }}(0)$ & Uniform $(0,0.5)^{\mathrm{i}}$ & $\mathrm{L}$ \\
\hline $\begin{array}{l}\text { Fraction of lung in liver } \\
\text { imaging region }\end{array}$ & f(lung, liver) & Normal $[0.02,0.01](0,1)^{\mathrm{ii}}$ & - \\
\hline $\begin{array}{l}\text { Fraction of lung in stomach } \\
\text { imaging region }\end{array}$ & f(lung, stom) & Normal $[0.02,0.01](0,1)$ & - \\
\hline $\begin{array}{l}\begin{array}{l}\text { Fraction } \\
\text { nanoparticles }\end{array}\end{array}$ & Small & Uniform $(0,1)$ & - \\
\hline $\begin{array}{l}\text { Fraction of Technetium bound } \\
\text { to nanoparticles }\end{array}$ & Bound & Uniform $(0,1)$ & - \\
\hline $\begin{array}{l}\text { Partition coefficient for free } \\
\text { Technetium }\end{array}$ & $\mathrm{P}_{1}$ & Uniform $(0,20)$ & - \\
\hline $\begin{array}{l}\text { Partition coefficient for small } \\
\text { particles }\end{array}$ & $\mathrm{P}_{0}$ & Uniform $(0,20)$ & - \\
\hline $\begin{array}{l}\text { Translocation rate from lung } \\
\text { to blood for free Technetium }\end{array}$ & Kv_lung 1 & 0.04 & $\mathrm{~L} / \mathrm{min}$ \\
\hline $\begin{array}{l}\text { Translocation rate from lung } \\
\text { to blood for small particles }\end{array}$ & $\mathrm{Kv}_{\text {_lung }}$ & Uniform $(0,0.1)$ & $\mathrm{L} / \mathrm{min}$ \\
\hline $\begin{array}{l}\text { Translocation rate from lung } \\
\text { to stomach lumen }\end{array}$ & Km_lung & Uniform $(0,0.1)$ & $\mathrm{L} / \mathrm{min}$ \\
\hline $\begin{array}{l}\text { Free Technetium renal } \\
\text { elimination rate }\end{array}$ & $\mathrm{Ke}_{-} \mathrm{renal}_{1}$ & Uniform $(0,1)$ & $\mathrm{L} / \mathrm{min}$ \\
\hline $\begin{array}{l}\text { Small particles } \\
\text { elimination rate }\end{array}$ & $\mathrm{Ke} \_r e n a l_{0}$ & 0 & $\mathrm{~L} / \mathrm{min}$ \\
\hline
\end{tabular}

\footnotetext{
${ }^{\mathrm{i}}$ Between brackets are the boundaries of the distribution

${ }^{\text {ii }}$ Between square braces are the mean and standard deviation of the distribution.
} 
TABLE 4

Model posterior parameter estimates.

\begin{tabular}{ll}
\hline Parameter & $\begin{array}{l}\text { Arithmetic mean and } \\
\text { standard deviation }\end{array}$ \\
\hline Small & $0.127 \pm 0.0113$ \\
Bound & $0.93 \pm 0.0158$ \\
f(lung,liver) & $0.0129 \pm 0.00437$ \\
f(lung,stom) & $0.00564 \pm 0.00327$ \\
$\mathrm{~K}_{\mathrm{v} \_l u n g \_0}(\mathrm{~L} / \mathrm{min})$ & $0.0165 \pm 0.000952$ \\
$\mathrm{P}_{-} 0$ & $0.445 \pm 0.0295$ \\
$\mathrm{~V}_{\mathrm{u} \_ \text {zero }}(\mathrm{L})$ & $0.0196 \pm 0.00779$ \\
$\mathrm{~K}_{\mathrm{m} \_ \text {lung }}(\mathrm{L} / \mathrm{min})$ & $0.0049 \pm 0.000868$ \\
$\mathrm{~K}_{\mathrm{e} \_ \text {renal_1 }}(\mathrm{L} / \mathrm{min})$ & $0.798 \pm 0.134$ \\
$\mathrm{P}_{\text {_1 }}$ & $0.499 \pm 0.164$ \\
\hline
\end{tabular}




\section{TABLE 5}

Model posterior parameter estimates.

\begin{tabular}{|c|c|}
\hline Parameter & $\begin{array}{l}\text { Mean and standard } \\
\text { deviation }\end{array}$ \\
\hline Small & $0.127 \pm 0.0113$ \\
\hline Bound & $0.93 \pm 0.0158$ \\
\hline f(lung,liver) & $0.0129 \pm 0.00437$ \\
\hline f(lung,stom) & $0.00564 \pm 0.00327$ \\
\hline $\mathrm{K}_{\mathrm{V}_{\text {_llung_0}}}(\mathrm{L} / \mathrm{min})$ & $0.0165 \pm 0.000952$ \\
\hline$P_{-} 0$ & $0.445 \pm 0.0295$ \\
\hline$\overline{\mathrm{V}}_{\mathrm{u} \_ \text {zero }}(\mathrm{L})$ & $0.0196 \pm 0.00779$ \\
\hline $\mathrm{K}_{\mathrm{m} \_ \text {lung }}(\mathrm{L} / \mathrm{min})$ & $0.0049 \pm 0.000868$ \\
\hline $\mathrm{K}_{\mathrm{e} \_ \text {renal_1 }}(\mathrm{L} / \mathrm{min})$ & $0.798 \pm 0.134$ \\
\hline$P_{-} 1$ & $0.499 \pm 0.164$ \\
\hline
\end{tabular}


FIG. 1. Schematic representation of the common basis for the physiologically based pharmacokinetic models we used for a human male. The body is subdivided into compartments describing organs or diffuse tissues. Nanoparticles or free technetium are transported or transferred through the compartments.

FIG. 2. Time course of radioactivity of stomach lumen and urine for five human subjects, based on Nemmar et al. data. We present model predicted data (lines) and actual data. Radioactivity is expressed as ratio of liver radioactivity. Black circles : Subject 1; white circles : subject 2; crosses : subject 3; plusses : subject 4; squares : subject 5.

FIG. 3. Time course of radioactivity of blood for five human subjects, based on Nemmar et al. data. We present model predicted data (lines) and actual data. Black circles : Subject 1; white circles : subject 2; crosses : subject 3; plusses : subject 4; squares : subject 5 . 


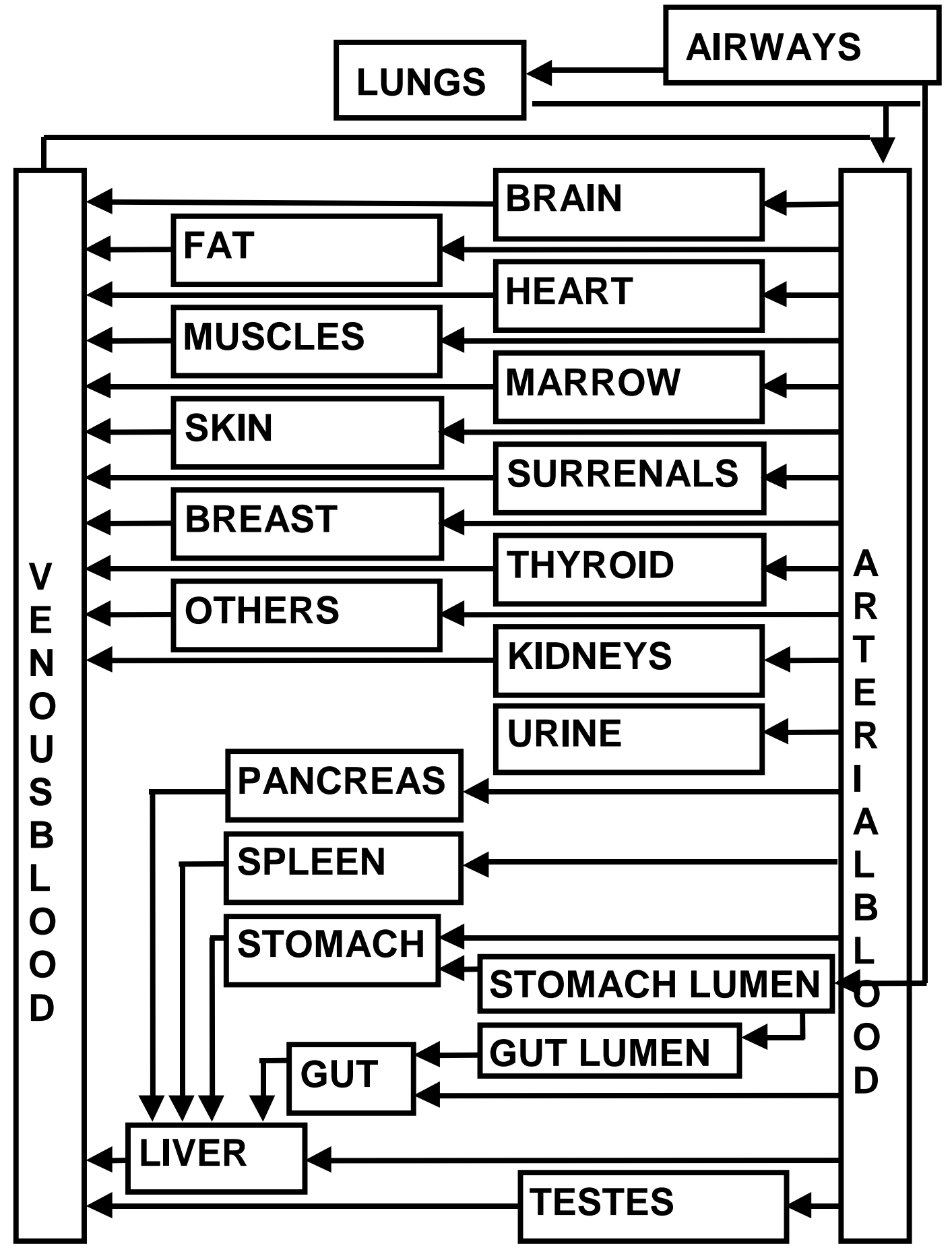

Figure 1. 


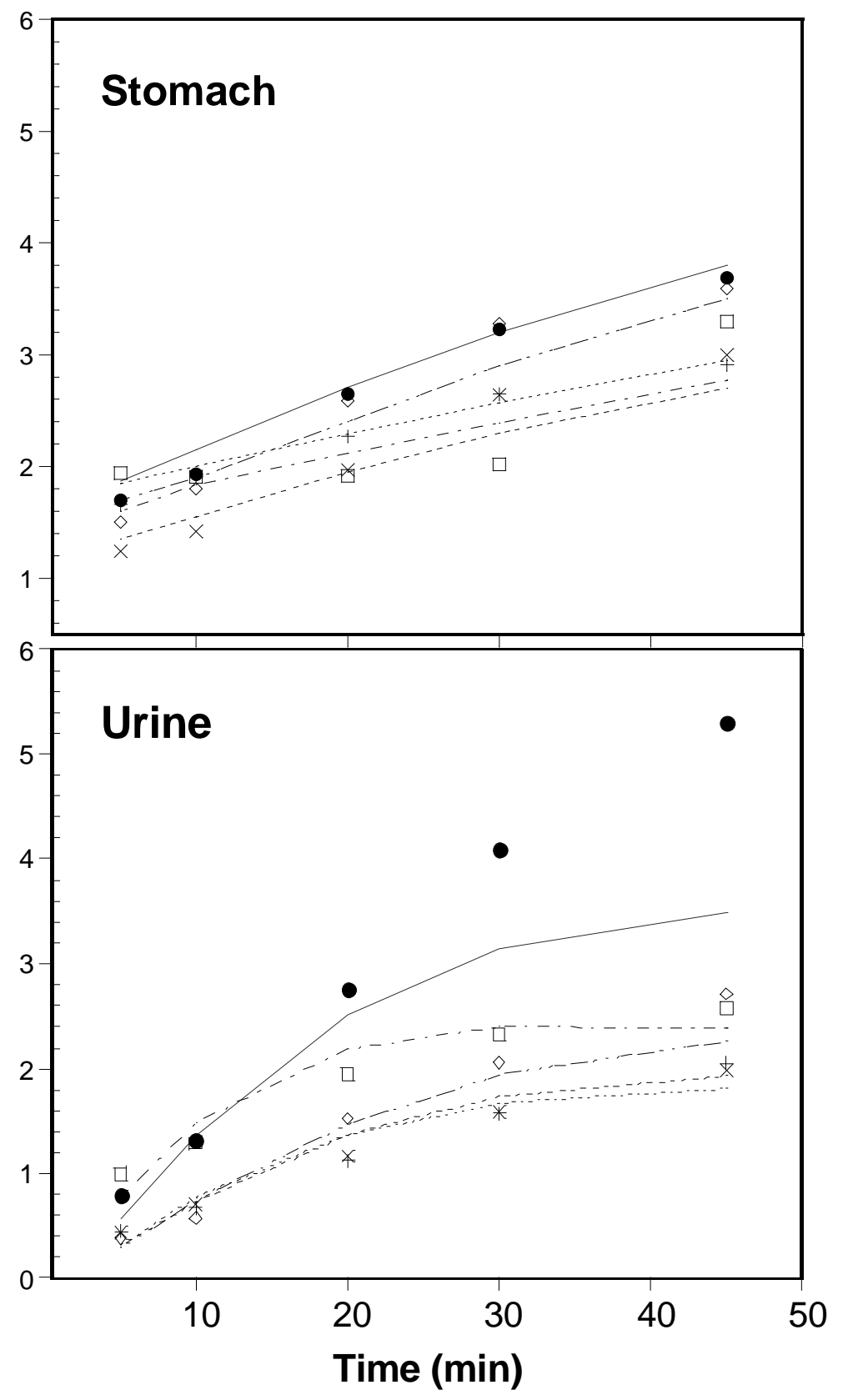

Figure 2. 


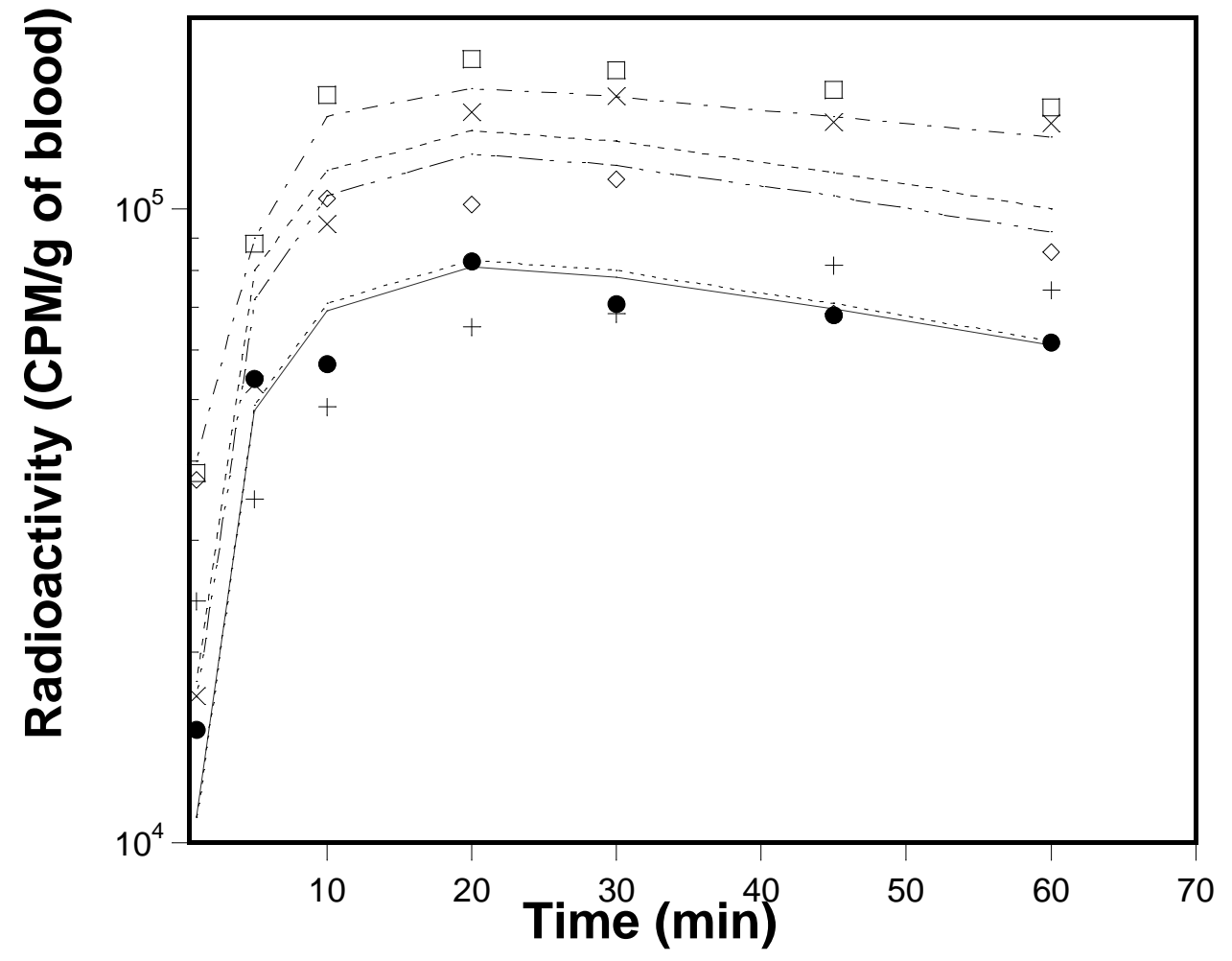

FIG. 3. 